\title{
Theoretical Study of College Mathematics Micro-teaching Construction
}

\author{
Youliang Han \\ Tangshan Normal University at Luan, HeBei Luan, 063700 \\ hanyouliang2016@163.com
}

Keywords: College; Mathematics; Teaching; Theory

\begin{abstract}
The study and application level of teaching strategies and abilities have a direct relationship. Teaching strategies is the decisive factor to master the level of teaching abilities, training students to master mathematics teaching strategies can promote the formation of students' comprehensive ability, which is important. Micro-teaching is a scientific methodology and modern educational technology training methods. So under the guidance of teaching theory, mathematics micro-teaching can improve the application of scientific methodology, modern educational technology, micro-economic theory and mathematics classroom activities method. It can practice teaching behavior as teaching strategies level were summarized, also can forming a controlled operable teaching strategies system and scientific training program. Micro-teaching has strong practical research on teaching strategies of training to fill the gaps in macro-teaching theory and mathematics teaching theory research. Micro-teaching is the same to the development of our own teaching practice situation at home and abroad; we believe that micro-teaching practice can build a system in visual theory and technology to train students to master the new curriculum process to adapt the concept of teaching strategies.
\end{abstract}

\section{Introduction}

Mathematics is to study the mathematics teaching theory and the discipline applied law, which is the study object of mathematics teaching system, namely mathematics teaching and learning interaction and unity. The purpose is to train students to have comprehensive ability in mathematics teaching. Practice shows that forming ability is a low to high gradual process, but also inseparable from practice. Training is also a teaching ability needed in the teaching practice under the guidance of teaching theory. If the students want to form a comprehensive teaching ability, we need to have some basic teaching skills. Otherwise, even if students enter the job, it is difficult to adapt to their roles as a comprehensive teaching capacity increased slowly. Teaching is the core of teachers. Teaching strategy is based on the teaching and learning activities and teaching behavior characteristic features, we can concentrate on describing, demonstration and imitation, which are basic and stable teaching behavior. Thus the level of learning and teaching strategies applied to the overall development of teaching abilities is directly related. To grasp the merits of teaching strategies is the decisive factor to master mathematics teaching strategies and promote the formation of students' comprehensive ability in mathematics teaching.

\section{The Connotation of College Mathematics Micro-teaching Construction}

The mathematics Micro-teaching relationship is the relationship between the personality and common, and it has the general characteristics of micro-teaching, but also to follow the special rules of mathematics teaching, which constitutes a micro-grid mathematics teaching connotation. We believe that micro mathematics teaching in modern mathematics education theory and science system are based on the principles of micro-teaching, the application of audio-visual media can train their mathematics teaching methods. In short, mathematics micro-teaching is teaching skills of training system. The essential characteristics of the micro-grid mathematics teaching are to follow the law. Mathematics teaching is a complex process involving many factors, such as the teaching practice in mathematics teaching skills has its own connotation and denotation determined, there is a clear scope, and mathematics micro-teaching is based on reductionist thinking. For example, the 
mathematics classroom teaching skills are combined with the mathematics characteristics, we will break down the math import to explain math.

\section{The Significance of College Mathematics Micro-teaching Construction}

Micro-Teaching Help Teaching Theory Transform into the Teaching Practice. Theorists engaged in the creation of educational research are usually more advanced, while because of the relatively low level of theory, which is difficult to freely apply to everyday teaching. Education theory is often slow to practice the teaching process, which the fact is that a long time cannot be improved. New theories, new methods in mathematics micro-teaching, the study of new materials and the use of new mathematics teaching strategies can greatly reduce the theory into practice process and promote the teaching theory to practical direction.

Micro-Teaching Helps Improve Teaching Abilities. The study and teaching skills of overall teaching strategy lays a good foundation for teaching practice. Complete classroom teaching process is the teaching skills, the integrated use of teaching strategies is repeatedly training, proficiency in order to form a perfect synthesis of art. Clear objectives and teaching strategies controllable operating specific training to facilitate the students to observe imitate, reduce the complexity of teaching, simulated teaching environment can reduce the psychological stress caused by the true teaching, so that students are more successful in taking the first from students to teachers step. Therefore Micro-teaching teaching ability of students is important.

Micro-Teaching Helps Enrich Mathematics Teaching Theory. Mathematics Micro-teaching specific to mathematics, what are the basic teaching skills and teaching mathematics teaching strategies it should have, what are the characteristics of the skills, strategies, and what form the law is, how to master, how to use and so on depth research, creating a capacity for mathematics teaching deep-rooted problems in the study. At the same time, the study of mathematics Micro-teaching, but also conducive to wealth Micro-teaching Theory. Research on this subject, to enrich Micro-teaching theory, increase the practicality reason perish, cultivate and improve students' teaching ability, perfect Curriculum System has a positive theoretical and practical significance.

\section{Theoretical Model of College Mathematics Micro-teaching}

We believe that the complete process of Micro-teaching includes theoretical study and practical training in two parts. Carry out the theory of learning is carried out after Micro-teaching practice training base, there is no theoretical guidance, the students do not know the rules and standards of training, and the training will be lost direction. Micro-teaching student's practical training is within the theory, or teaching strategies required implementing rule level. Leaving the practice of teaching theory is empty, abstract, theoretical teaching only put teaching practice, it is fresh, there is life, in order to be accepted student, master, into its own thing. Mathematics Micro-teaching is a complete integration of theory and practice as a whole. To explain the main theoretical study, practical training and experience is a student-based, which is the core of the demonstration and evaluation of the entire system. Mathematics Micro-teaching entire training system includes a target system, methodology, evaluation and management system, respectively Mathematics Micro-teaching training process required for various conditions.

Theoretical Study of College Mathematics Micro-teaching. Content Mathematics Micro-teaching reason perish learning from a broad sense including education, psychology, educational psychology and pedagogy of mathematics and other learning theories in general among public courses throughout. Micro-teaching Theory We are here to learn mathematics primarily with Micro-teaching training closely related content, which mainly by way of teaching, allowing students to receive, specifically including the following aspects.

Import of ten basic classroom teaching skills, teaching language, ask questions, explain, change, enhancement, presentation, writing on the blackboard, end and classroom conduct a comprehensive study of organizational skills, including skills of meaning, functions, types, elements, Application Notes and typical examples of lesson plans and so on. Teaching students the skills to do this ten can 
confirm, understand its function and application principles. These teaching skills only in theory talk, do not conduct individual training, basic skills training into the training carried out teaching strategies. This not only saves time, but also largely avoided in the process of teaching students the basic teaching skills to put together a simple mechanical tendencies.

Secondly, micro instructional design and preparation of lesson plans. The main contents of Micro-teaching training are to train a variety of teaching skills. But the wonderful performance of teachers in the classroom, there must be a reasonable teaching designed to support, in spite of the classroom is complex, the teachers cannot exhaustive of all of its potential, but it still should actively prepare teachers, design and planning of each lesson, students should master the instructional design knowledge and writing lesson plans. As it relates to the use of a variety of teaching skills and regulation, still need to carefully designed and written into lesson plans. Especially for the relatively poor teaching experience for students, instructional design and preparation of lesson plans is especially important.

Finally, the students during the training process Micro-teaching, when the feedback evaluation is likely to occur, "mouth freely their opinion and not" situation, and my heart seemed to understand, but is unable to speak. Therefore, in theory learning part, we need to briefly describe how feedback to students, and the basics of evaluation.

Practical Training of College Mathematics Micro-teaching. In mastering the theoretical knowledge and skills training, and skills training to understand the basic pattern, then specific teaching content, ready Micro-teaching training lesson plans. Preparation of the classroom lesson plans, group students take turns playing the role of teachers and students, lecture controlled within minutes, lectures situation recorded by a video camera, and then in small groups, lectures reproduction process were discussed, and control the classroom Evaluation criteria scoring skills of each individual skill, a skill if found the problems highlighted, and then separate out the training. Evaluation is an important part of Micro-teaching System. Flange D, a famous American educator sees no evaluation there is no education, no scientific evaluation would be no effective education, there is no advanced technology to participate in the evaluation, there is no modern education. The application of modern scientific methods to carry out micro-teaching, teaching scientifically measured and evaluated in Micro-teaching is to improve the effectiveness of Micro-teaching important guarantee.

Implement Step of College Mathematics Micro-teaching. We believe that the ideal of mathematics Micro-teaching implementation process can be divided into several stages.

The Stage of Theoretical Learning

This stage is divided into two parts. The first part is the basic theory of the learning phase, these theories learning is an important part of preparing for the second Micro-teaching learning is the basic theory of learning Micro-teaching, this phase of the study before the Micro-teaching practice training, mainly to students Introduction Micro-teaching Training based wood content, so that students in the theoretical level of basic teaching skills and teaching strategies to be in control.

The Stage of Preparing for the Implementation

Training method is to classroom teaching into different individual teaching skills were training, a time intensive training one or two skills, so easy to grasp. After being trained on the skills, trainees should choose appropriate teaching content, instructional design based on the set teaching objectives, and to prepare a more detailed lesson plans. Micro-teaching lesson plans have characteristics different from the general lesson plan, it should be described in detail teachers' behavior that is applied skills and student learning behaviors include expected reaction.

The Stage of Outstanding Teaching Demonstration

After each student has a theoretical basis for selection of some excellent teachers recording, organizing students to watch, in addition, take advantage of the opportunity to organize a school uniform trainee, experience the elementary school mathematics classroom atmosphere. The purpose is to help students obtain some basic perceptions of right before the simulated teaching, know how teaching practice at the level of implementation. 


\section{References}

[1] Li Hongying, ginger pine primary school English teaching skills development and micro-teaching future [J]. Sichuan College of Education. 2007 (02)

[2] Chen Jiuling. Micro-teaching and future teachers [J]. EDUCATION ARTICLE (HEAD). 2007 (01)

[3] Zhang Guirong, the validity of research Chu Tien-chi, Jia Lizhen. Micro-teaching skills training [J]. Education and Vocation. 2007 (03)

[4] Wong Chung Ji-effective way to improve middle school mathematics classroom teaching skills. - Micro - study Mathematics Teaching [J] .2006 Mathematics Teaching (11) 